\title{
A Blueprint for Target Motion: fMRI Reveals Perceived Sequential Complexity to Modulate Premotor Cortex
}

\author{
Ricarda I. Schubotz and D. Yves von Cramon \\ Max-Planck-Institute of Cognitive Neuroscience, 04103 Leipzig, Germany
}

Received November 12, 2001

\begin{abstract}
The execution of movements that are guided by an increasingly complex target motion is known to draw on premotor cortices. Whole-brain functional magnetic resonance imaging was used to investigate whether, in the absence of any movement, attending to and predicting increasingly complex target motion also rely on premotor cortices. Complexity was varied as a function of number of sequential elements and amount of dynamic sequential trend in a pulsing target motion. As a result, serial prediction caused activations in premotor and parietal cortices, particularly within the right hemisphere. Parametric analyses revealed that the right ventrolateral premotor cortex and the right anterior intraparietal sulcus were the only areas that, in addition, covaried positively with both behavioral and physical measures of sequential complexity. Further areas that covaried positively with increasing task difficulty reflected influences of both number and trend manipulation. In particular, increasing element number drew on dorsal premotor and corresponding posterior intraparietal regions, whereas increasing trend drew on the visual motion area and area V4. The present findings demonstrate that premotor involvement directly reflects perceptual complexity in attended and predicted target motion. It is suggested that when we try to predict how a target will move, the motor system generates a "blueprint" of the observed motion that allows potential sensorimotor integration. In the absence of any motor requirement, this blueprint appears to be not a byproduct of motor planning, but rather the basis for target motion prediction. 2002 Elsevier Science (USA)
\end{abstract}

\section{INTRODUCTION}

The ease or effort with which sequential event patterns can be detected, acquired, and, if required, responded to by movements strongly depends on their complexity, which is determined by various features. These include for instance the sequence length or total number of elements of which a sequence is composed (e.g., "2, 8, 5" is less complex than "2, 8, 5, 1"). F urther- more, structural properties such as repetitions or alternations permit a segmentation of the entire sequence into chunks or substrings and thereby facilitate learning and memory (e.g., " 1 , 2, 3, 1, 2, 3" and " $1,1,2$, $2,3,3$ " are less complex than " $1,3,2,3,1,2$ ").

The sequential order of events is critical for both perception and action. The detection and encoding of sequential orders enables us to set up specific expectations about ongoing events and, if required, to adapt sequential motor responses. Thus, sequential event anticipation allows, for instance, tracking of regular target motion with minimal phase lag in smooth-pursuit eye movement (Lekwuwa and Barnes, 1996; Kawashima et al., 1998) or sensory-guided finger responses in serial reaction time (SRT) paradigms (Zhuang et al., 1998; Patel and Balaban, 2000).

On the neural level, increased complexity of serially guided movements has been found to increase activations in a network of cortical areas, including the lateral premotor cortex (PM), the (pre) supplementary motor area (preSMA, SMA), and the primary motor cortex, and the intraparietal sulcus (IPS) that project to these motor regions (for an overview, see Harrington et al., 2000). In particular, multiple distinct circuits connecting lateral premotor and parietal areas are taken to transform and integrate serial sensory and serial motor events in a sensorimotor mapping process (Rizzolatti et al., 1998; Matelli and Luppino, 2001; Passingham, 1993; Wise et al., 1997; Halsband and Freund, 1990). Up to now, however, increasing activation within considered premotor and parietal areas has been reported in SRT-like paradigms and therefore account for effects of sequential complexity on the movement level. In contrast, sequential complexity on the perceptual level has been almost neglected in imaging studies. Even though some SRT studies have manipulated the sequential complexity of the guiding stimulus to increase the sequential complexity of the guided movement, no attempt has been made to disentangle confounded effects of sequential complexity on the perceptual and motor levels. Accordingly, the total number of sequential elements in the guiding stimulus 
is confounded with the total number of employed motor effectors. Likewise, the number of stimulus switches (stimulus-stimulus transitions) is confounded with the number of effector "switches" (finger-finger transitions). Accordingly, we are still almost ignorant about the brain correlates of sequential complexity on the perceptual level.

Traditionally, perceptual functions have been ascribed to posterior areas, whereas motor functions have been ascribed to frontal areas. This view has changed dramatically within recent years as researchers became more and more interested in brain regions that mediate between sensory and motor require ments. Research on macaques has shown that sensorimotor mapping takes place on the single-cell level, particularly within lateral PM (in monkeys, area 6). Thus, premotor neurons discharge not only during movement, but also during sensory (Rizzolatti et al., 1981b, 1988; Gentilucci et al., 1983, 1988) and somatosensory (Rizzolatti et al., 1981a) stimulation or both (Gentilucci et al., 1988; Fogassi et al., 1996a,b; Graziano and Gandhi, 2000). These properties apply particularly to the ventrolateral premotor cortex (PMv) (Graziano et al., 1997) and to its major parietal projection zone, the IPS (Duhamel et al., 1998). The coexistence of perceptual and motor responses within the PM is taken to reflect "action vocabularies," which can be addressed either by mere perception (external stimulation) or by internal action planning (F adiga et al., 2000).

The present study used whole-brain functional magnetic resonance imaging ( $\mathrm{fMRI}$ ) to investigate whether-in the absence of any movement-increased sequential complexity of a perceived target is reflected by an increase of activation in premotor areas and their parietal projection sites. We employed a serial prediction task, which is a perceptual counterpart of the classical serial reaction task introduced by $\mathrm{N}$ issen and Bullemer (1987) and which permits the testing of performance in a perceptual sequential task without sequential motor responses. In previous fMRI studies, this paradigm caused significant activations in several premotor and parietal regions, substantially overlapping with those reported in sequential finger movements (Schubotz et al., 2000; Schubotz and von Cramon, 2001a,b, 2002a,b). Based on these findings and in accordance with the view that the PM is crucial not only in purely motor preparation, but also in sensory and sensorimotor mapping functions as considered above, we have argued that the production and the perception of serial orders probably share a common neural substrate. The present study was intended to test this view further using a parametric manipulation of sequential perceptual complexity.

Sequential complexity in a pulsing target motion was varied as a function of two factors: the number of sequential elements (number) and their sequential trend (trend). While in SRT-like paradigms, sequential number is frequently employed to manipulate sequence complexity, the manipulation of sequential trend is newly introduced in the present study. Trend was stimulated by adding a constant positive or negative value " $a$ " to corresponding elements " $e$ " in a sequence, such that sequences such as, e.g., "el, e2, e1, e2 + a, el, e2 + 2a, e1, e2 + 3a, ..." were generated. This manipulation was inspired by the fact that many sequential patterns that we observe in everyday life, particularly in observed motion, are not strictly repetitive. Rather, we experience targets showing a spatial or temporal decrease or increase, depending for instance on their departure or arrival, on their acceleration or deceleration. Even in highly repetitive locomotion, the moving being has at least a spatial trend-it moves away from or approaches the observer. Aiming at a perceptual stimulation that corresponds to such experiences in real life, we presented sequences of both different lengths and different amounts of dynamic trends.

\section{MATERIALS AND METHODS}

\section{Participants}

Eighteen healthy right-handed students (10 male, 8 female; aged $21-30$ years, mean age 24.8 years) participated in the experiments. After being informed about potential risks and screened for contraindications by a physician of the institution, subjects gave informed consent before participating in the fMRI experiment. The experimental standards were approved by the local ethics committee of the University of Leipzig. All data were handled anonymously.

\section{Procedure}

Participants underwent a 1-h training session 5 days before each main experiment. In the MRI session, participants were supine on the scanner bed with their right index and middle fingers positioned on the response buttons. To prevent postural adjustments, the participants' arms and hands were carefully stabilized by tape. In addition, form-fitting cushions were used to prevent arm, hand, and head motion. Participants were provided with earplugs to attenuate scanner noise. I mmediately prior to the functional imaging session, participants spent $20 \mathrm{~min}$ in the scanner, so that they could acdimate to the confinement and sounds of the MR environment.

\section{Stimuli and Tasks}

The stimulus material consisted of 12 circles with diameters ranging from 0.6 to 2.8 degrees of visual angle. Within each trial, 12 stimuli were presented subsequently at a rate of 1 per 500 ms without temporal gaps, announced by a preceding task cue, and followed by a response feedback (see Fig. 1). N ote that 


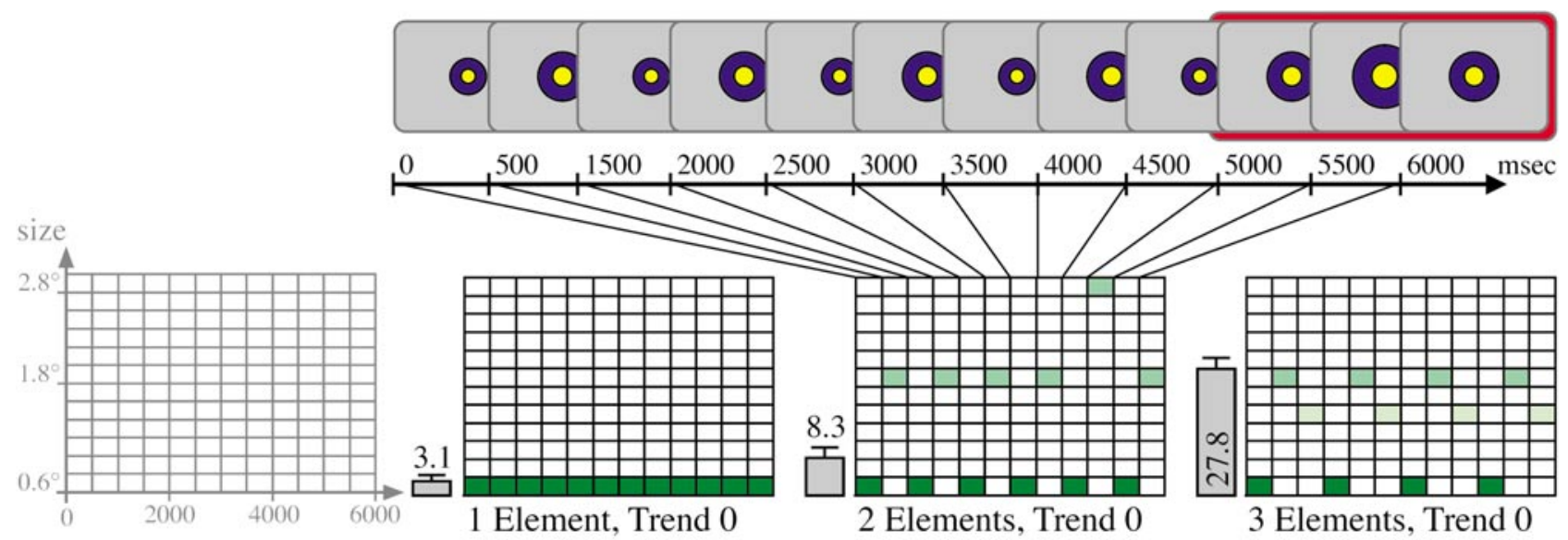

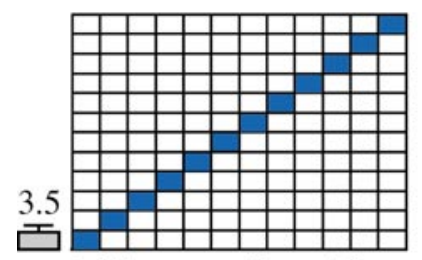

1 Element, Trend 1

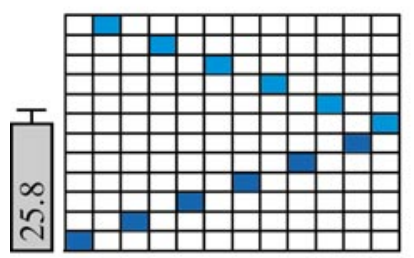

2 Elements, Trend 1

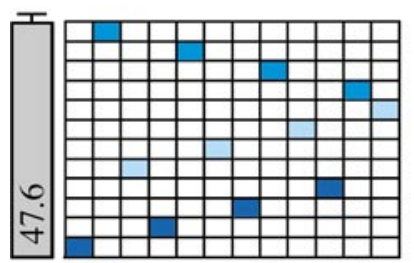

3 Elements, Trend 1

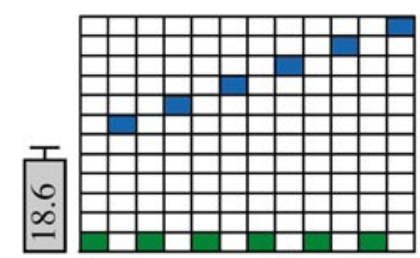

2 Elements, Trend 0.5

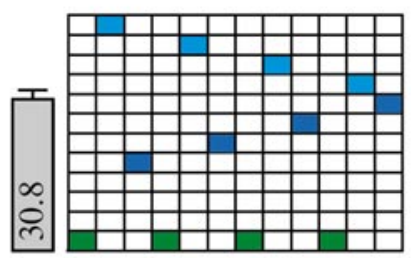

3 Elements, Trend 0.6

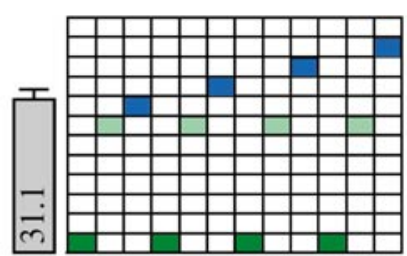

3 Elements, Trend 0.3

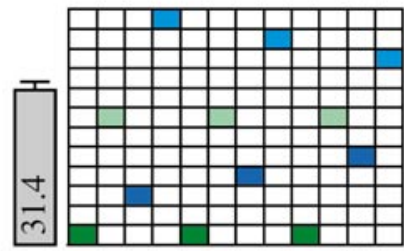

4 Elements, Trend 0.5

Baseline
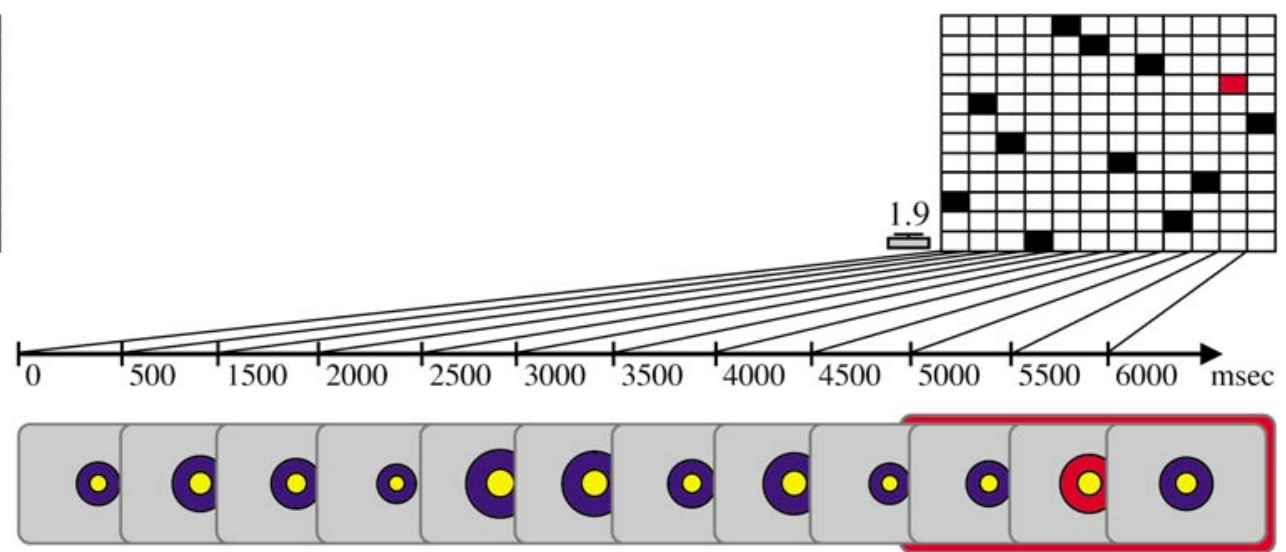

FIG. 1. Schematic examples of all types of stimulus sequences and corresponding error rates. For each sequence type, a size by time diagram shows a typical course of the pulsing target motion within one trial, composed of 12 pictures presented for 500 ms each. Elements with a trend of zero $\left(E_{0}\right)$, indicated in green, and elements with a constant positive trend $\left(E_{1}\right)$, indicated in blue, were taken to build 1-, 2-, 3-, and 4-element sequences. The 1st, 2nd, 3rd, and 4th elements within a sequence are indicated in different shades of the corresponding color, from dark to light. Examples for the visual presentation are shown for one serial prediction condition (top) and the baseline condition (bottom). In the sequence conditions, participants were asked to build up expectations about the last 3 stimuli of a trial (as highlighted in red). In cases of successful prediction, participants were able to indicate whether any stimuli deviated from the sequential pattern introduced by the first 9 stimuli within a trial ( $50 \%$ of all presented trials). In contrast, sequential order was irrelevant to indicate color deviants, as required in the baseline condition. Both presentation examples contain a deviant stimulus on the 11th position. The gray bars on the left sides of the schemata display the mean error rates and the standard errors in the corresponding tasks. 


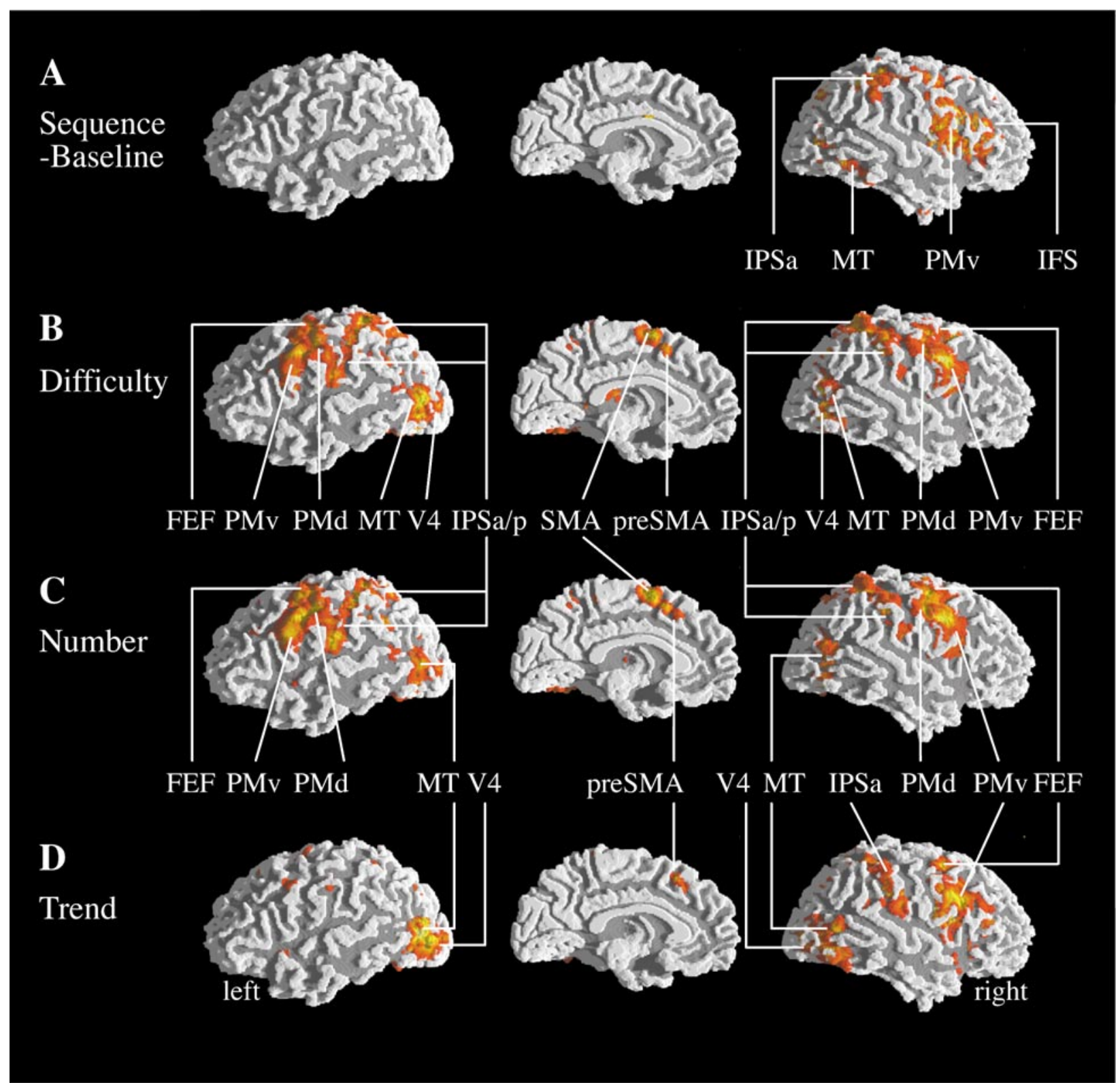

FIG. 2. Brain correlates of predicting increasingly complex target motion. Group-averaged activations of voxels exceeding a threshold of $Z=3.01$ are superimposed onto a T1-weighted individual brain that underwent a white matter segmentation with partially filled sulci. Right panels show the surface of right hemisphere, left panels show the left hemisphere, and middle panels show the left hemisphere from the sagital midline section $(x=0)$ for the contrast sequence- baseline $(A)$, and all parametric analyses (B, C, and D). (A) Serial prediction of target motion, relative to the baseline condition. For this contrast, the two easiest levels of complexity of the serial prediction task (one-element sequences) were collapsed and then contrasted with basel ineto exclude confound with effects of difficulty. (B) Effects of increasing sequential complexity in target motion, indicated by voxels correlated positively with difficulty in serial prediction. (C) Effects of increasing sequential complexity in target motion, indicated by physical stimulus properties, i.e., number of sequential elements. (D) Amount of sequential trend within target motion.

this kind of stimulus presentation resulted in the impression of a regularly pulsing target motion. The stimulus presentation lasted $6 \mathrm{~s}$; the intertrial interval was $6 \mathrm{~s}$.

A serial prediction task (sequence) and a control condition (baseline) were presented in a mixed trial design. In sequence, trials were announced by the cue "order," indicating that participants were required to attend to the sequential order of the circles' size. The participants' task was to judge whether the last three stimuli within a trial matched the stimuli that they expected. In contrast, condition baseline was announced by the cue "col or," indicating that participants were required to attend to the circle color. 
TABLE 1

Anatomical Area, Mean Talairach Coordinates ( $x, y, z)$, and Maximal Z Scores of Significant Activations in Sequential Prediction (Easiest Levels of Condition Sequence) versus Baseline

\begin{tabular}{lcccccccc}
\hline & & \multicolumn{5}{c}{ Sequence vs Baseline } & & \\
\cline { 2 - 7 } Anatomy & Hemisphere & $\mathrm{x}$ & $\mathrm{y}$ & $\mathrm{z}$ & $\mathrm{Z}$ & Difficulty & Number & Trend \\
\hline PMV & $\mathrm{R}$ & 51 & 3 & 18 & 5.6 & $*$ & $*$ & $*$ \\
IFS & $\mathrm{R}$ & 41 & 22 & 19 & 4.9 & - & $*$ & $*$ \\
IPSa & $\mathrm{R}$ & 37 & -40 & 39 & 4.6 & $*$ & $*$ & - \\
CE & $\mathrm{L}$ & -26 & -72 & -20 & 4.7 & $*$ & $*$ \\
CAU & $\mathrm{R}$ & 11 & 7 & 13 & 3.7 & $*$ & $*$ \\
\hline
\end{tabular}

Note. The three-columns on the right indicate which of these areas covaried positively with measures of increasing sequential complexity (not (-), significant $(*)$ ). PMV, ventrolateral premotor cortex; IFS, inferior frontal sulcus; IPSa, anterior intraparietal sulcus; CE, cerebellar cortex; CAU, caudate nucleus.

In $50 \%$ of all trials in sequence and baseline, respectively, one of the last three stimuli was a deviant. In sequence, deviant stimuli were those which did not match the sequential pattern of the first nine stimuli, i.e., which were unexpected in size. In baseline, deviant stimuli were a predefined target with a deviant color, such that the sequential order of the first nine stimuli was irrelevant for identifying deviants in this condition. In contrast to sequence, all stimuli within each baseline trial were presented in randomized (nonsystematic) order. Under both experimental conditions, performance was tested by a forced choice response at the end of each trial (deviant = right index finger; no deviant $=$ right middle finger).

Trials in sequencediffered with regard to the sequential complexity of the stimulus train. Sequential complexity was varied as a function of two factors: the number of sequential elements and their sequential trend. Elements with a trend of zero $\left(E_{0}\right)$ and elements with a constant positive trend $\left(E_{1}\right)$ were taken to build $1-, 2-, 3-$, and 4-element sequences. Overall, 10 different sequence types (2 1-element, 3 2-element, 4 3-element, 1 4-element sequences) were employed, as listed schematically in Fig. 1. Note that in the sequence subcondition with 1 element and a trend of zero, stimuli had to be presented with temporal gaps of $20 \mathrm{~ms}$, and thus by a rate of 1 per 480 ms, to keep the perceptual impression of a pulsing target motion similar for all subconditions of sequence.

\section{Data Acquisition}

I maging was performed at 3T on a Bruker Medspec $30 / 100$ system equipped with the standard bird cage head coil. Subjects were supine on the scanner bed, and cushions were used to reduce head motion. Slices were positioned parallel to the bicommissural plane (ACPC), with 16 slices (thickness $5 \mathrm{~mm}$, spacing $2 \mathrm{~mm}$ ) covering the whole brain. A set of two-dimensional anatomical images was acquired for each subject immediately prior to the functional experiment, using a
MDEFT sequence $(256 \times 256$ pixel matrix $)$. Functional images in-plane with the anatomical images were acquired using a single-shot gradient EPI sequence (TE $=30 \mathrm{~ms}, 64 \times 64$ pixel matrix, flip angle $90^{\circ}$, field of view $192 \mathrm{~mm}$ ) sensitive to BOLD contrast. During each trial, eight images were obtained from 16 axial slices each at the rate of $2 \mathrm{~s}$ per image (=16 slices). In a separate session, high-resolution whole-brain images were acquired from each subject to improve the localization of activation foci using a T1-weighted threedimensional segmented MDEFT sequence covering the whole brain.

\section{Data Analysis}

The fMRI data were processed using the software package Lipsia (Lohmann et al., 2001). In the preprocessing, low-frequency signals (frequencies due to global signal changes such as respiration) were suppressed by applying a 1/120-Hz temporal high-pass filter. This filter length was calculated in the following way: twice the length of one complete oscillation, i.e., minimal gap between two trials of the same experimental condition $=2 \times 60 \mathrm{~s} \approx 120 \mathrm{~s}$. Because low frequencies were removed, temporal filtering also effected a signal control correction. To correct for the temporal offset between the slices acquired in one image, a sinc-interpolation algorithm based on the Nyquist-Shannon Theorem was employed. To correct for movements, the images of the fMRI time series were geometrically aligned using a matching metric based on linear correlation.

The anatomical registration was done in three steps. First, the anatomical slices geometrically aligned with the functional slices were used to compute a transformation matrix, containing rotational and translational parameters, that registers the anatomical slices with the three-dimensional reference T1 data set. Second, each individual transformation matrix was scaled to the standard Talairach brain size $(x=135, y=175$, $z=120 \mathrm{~mm}$; Talairach and Tournoux, 1988) by apply- 
TABLE 2

Anatomical Specification, Hemisphere, Mean Talairach Coordinates ( $x, y, z)$, and Maximal Z Scores of Significantly Activated Voxels Correlated Positively with Increasing Sequential Complexity as Measured by Prediction Difficulty, Number of Sequential Elements, and Sequential Trend

\begin{tabular}{|c|c|c|c|c|c|c|c|c|c|c|c|c|c|}
\hline \multirow[b]{2}{*}{ Anatomy } & \multirow[b]{2}{*}{ Hemisphere } & \multicolumn{4}{|c|}{ Difficulty } & \multicolumn{4}{|c|}{ Number } & \multicolumn{4}{|c|}{ Trend } \\
\hline & & $x$ & $y$ & z & Z & $x$ & $y$ & z & Z & $x$ & $y$ & z & Z \\
\hline SMA & $\mathrm{L}$ & -2 & 1 & 56 & 4.5 & -3 & 0 & 56 & 4.8 & & & & \\
\hline \multirow{2}{*}{ FEF } & $\mathrm{R} / \mathrm{L}$ & -5 & 11 & 47 & 4.0 & $\begin{array}{r}6 \\
-21\end{array}$ & $\begin{array}{r}17 \\
-7\end{array}$ & $\begin{array}{l}45 \\
43\end{array}$ & $\begin{array}{l}4.4 \\
4.7\end{array}$ & -5 & 19 & 46 & 4.3 \\
\hline & $\mathrm{R}$ & 26 & -9 & 50 & 4.2 & 26 & -9 & $\begin{array}{l}45 \\
50\end{array}$ & $\begin{array}{l}4.1 \\
5.0\end{array}$ & 24 & 0 & 47 & 5.1 \\
\hline \multirow[t]{2}{*}{$\mathrm{PMd} / \mathrm{MI}$} & $\mathrm{L}$ & -35 & -3 & 48 & 4.9 & -37 & 0 & 46 & 5.1 & & & & \\
\hline & $\mathrm{R}$ & 43 & -7 & 50 & 4.8 & 43 & -7 & 50 & 5.2 & & & & \\
\hline \multirow[t]{2}{*}{ supPMv } & L & -54 & 0 & 36 & 4.3 & -50 & -1 & 34 & 4.8 & & & & \\
\hline & $\mathrm{R}$ & 52 & -1 & 33 & 5.4 & 43 & -1 & 36 & 5.0 & & & & \\
\hline \multirow[t]{2}{*}{ infPMv } & L & & & & & -52 & 5 & 23 & 4.6 & & & & \\
\hline & $\mathrm{R}$ & 51 & 4 & 20 & 4.5 & & & & & 50 & 1 & 20 & 5.5 \\
\hline \multirow[t]{3}{*}{ IPSa } & L & -54 & -20 & 21 & 5.1 & $\begin{array}{l}-56 \\
-44\end{array}$ & $\begin{array}{l}-22 \\
-26\end{array}$ & $\begin{array}{l}22 \\
37\end{array}$ & $\begin{array}{l}5.6 \\
5.2\end{array}$ & & & & \\
\hline & L & -35 & -38 & 54 & 5.2 & & & & & & & & \\
\hline & $\mathrm{R}$ & 52 & -30 & 40 & 5.1 & 51 & -30 & 39 & 5.1 & 51 & -26 & 30 & 5.0 \\
\hline \multirow[t]{3}{*}{ IPSp } & L & & & & & -28 & -41 & 53 & 4.8 & & & & \\
\hline & L & -22 & -55 & 48 & 5.8 & -21 & -55 & 48 & 5.9 & & & & \\
\hline & $\mathrm{R}$ & 26 & -51 & 50 & 5.0 & 30 & -50 & 49 & 5.0 & & & & \\
\hline \multirow[t]{2}{*}{ V5 (MT) } & L & -48 & -72 & 5 & 4.8 & -40 & -68 & 6 & 4.4 & -44 & -74 & 7 & 5.3 \\
\hline & $\mathrm{R}$ & 39 & -67 & 15 & 4.7 & 42 & -58 & 13 & 4.9 & 53 & -60 & 11 & 4.1 \\
\hline \multirow{2}{*}{ V4 } & L & -39 & -72 & -2 & 4.9 & & & & & -35 & -80 & -1 & 5.6 \\
\hline & $\mathrm{R}$ & 38 & -67 & 0 & 4.5 & & & & & 38 & -68 & 0 & 4.8 \\
\hline \multirow[t]{2}{*}{ CAU } & L & -15 & 15 & 7 & 3.3 & -16 & 14 & 9 & 3.6 & & & & \\
\hline & $\mathrm{R}$ & 13 & 14 & 6 & 3.1 & 13 & 14 & 5 & 3.3 & & & & \\
\hline \multirow[t]{2}{*}{ CE } & L & -22 & -70 & -13 & 4.5 & -29 & -64 & -15 & 4.9 & & & & \\
\hline & $\mathrm{R}$ & 31 & -59 & -14 & 4.5 & 30 & -59 & -15 & 4.7 & & & & \\
\hline
\end{tabular}

Note. SMA, supplementary motor area; PreSMA, presupplementary motor area; FEF, frontal eye field; PMd, dorsolateral premotor cortex; MI, primary motor cortex; supPMv, superior ventrolateral premotor cortex; IPSp, posterior intraparietal sulcus; MT, motion area. For other abbreviations, see Table 1.

ing linear scaling. Third, these normalized transformation matrices were applied to the individual functional raw data. Linear normalization was improved by an additional nonlinear normalization (Thirion, 1998). Slice gaps were scaled using a trilinear interpolation, generating output data with a spatial resolution of $3 \mathrm{~mm}^{3}$.

The statistical analysis was based on a least squares estimation using the general linear model for serially autocorrelated observations (random effects model) (Friston, 1994; Worsley and Friston, 1995; Zarahn et al., 1997). The design matrix was generated with a synthetic hemodynamic response function (Friston et al., 1998; J osephs et al., 1997). To avoid confounding effects from odd stimuli, all trials containing sequential deviant stimuli were excluded from both direct task contrasts and parametric analyses. For each trial, the event was set on the fifth stimulus (2 s after stimulus sequence onset), because thereafter only the minimal number of stimuli required to recognize the sequential pattern were presented, so that serial prediction could begin. The model equation, including the observation data, the design matrix, and the error term, was convolved with a Gaussian kernel of dispersion of $4 \mathrm{FWHM}$.

In the following, contrast maps, i.e., estimates of the raw score differences between specified conditions, were generated for each subject. As the individual functional datasets were all aligned to the same stereotactic reference space, a group analysis was subsequently performed. A one-sample t test of contrast maps across subjects was computed to indicate whether observed differences between conditions were significantly distinct from zero ( $Z \geq 3.09$ ) (Holmes and Friston, 1998).

The effect of sequential complexity was investigated in two ways. The first analysis was run with the regressor difficulty to model the effects of sequential complexity as measured by behavioral performance. In this performance-driven analysis, we thus took the view that sequential complexity is reflected by the error rate in serial prediction. To this end, the mean error rate within each of the 10 subconditions of sequence were computed for each single subject. Subsequently, these values were taken as subject-specific 


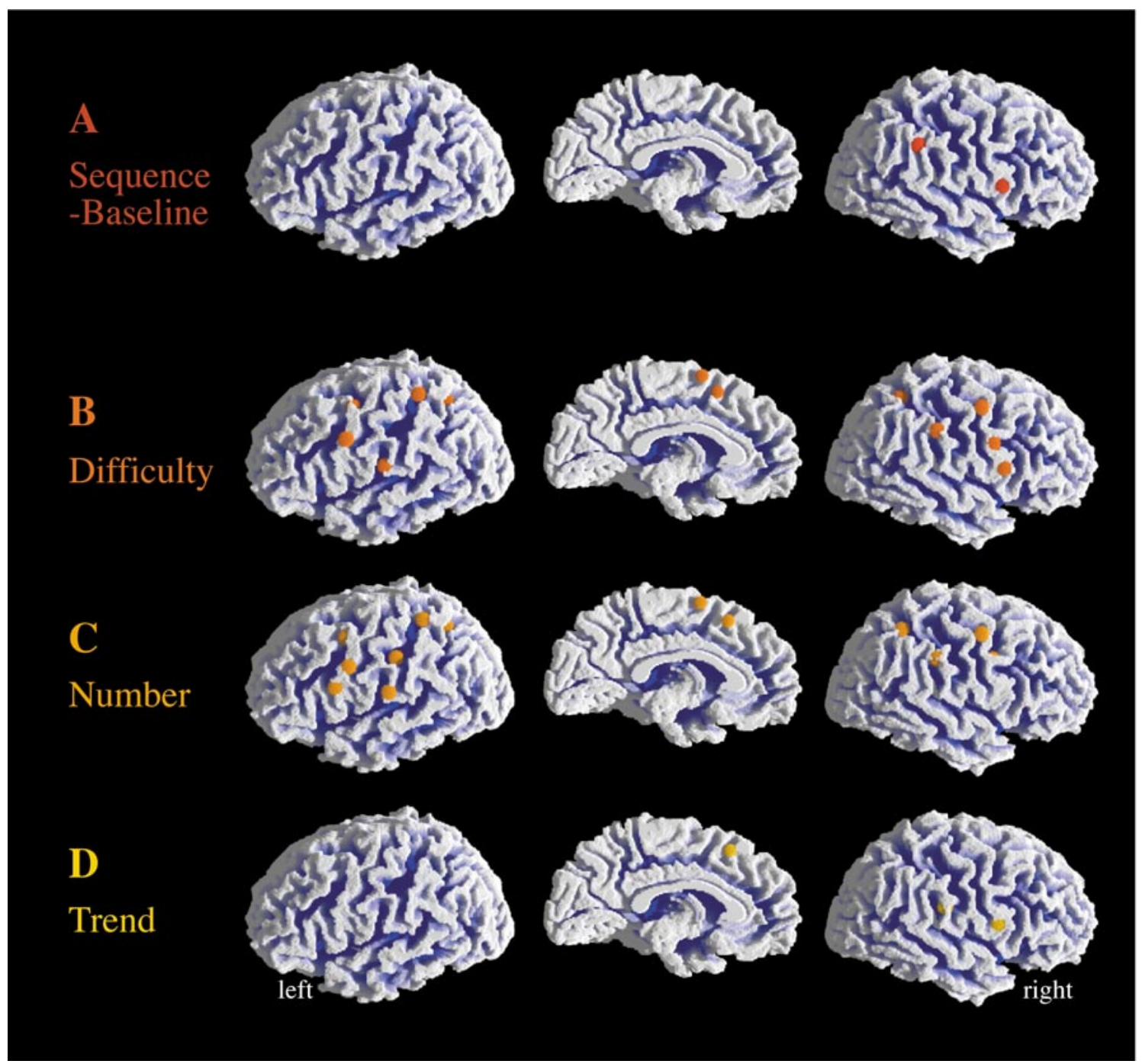

FIG. 3. Schematic comparison of premotor and parietal activation foci obtained in the present study. (A) Contrast sequence-baseline (B) Increasing difficulty of predicting target motion. (C) Increasing number of sequential elements in target motion. (D) Increasing sequential trend in target motion. Foci are plotted on an individual brain. Right panel shows the surface of the brain from top right and left panel from top left.

regressors in the general linear model during parameter estimation (Büchel et al., 1996, 1998).

The second analysis was run with the two separate regressors number and trend to model the effects of sequential complexity as measured by physical stimulus properties. In this stimulus-driven analysis, we thus took the view that brain areas which are sensitive to sequential target complexity should respond according to the physical stimulus properties which determine complexity. The regressor number had the values $1,2,3$, or 4 . The values for the regressor trend, in contrast, were computed as the weighted mean (sum of trends/number of elements). Thus, the trend was 0 for sequences exclusively made of el ements with a trend of zero (pure $E_{0}$ sequences) and 1 for pure $E_{1}$ sequences. For mixed $E_{0}-E_{1}$ sequences, trend had a value between 0 and 1 . This was 0.5 for both $1 \mathrm{E}_{0} / 1 \mathrm{E}_{1}$ and $2 \mathrm{E}_{0} / 2 \mathrm{E}_{1}, 0.6$ for $1 \mathrm{E}_{0} / 2 \mathrm{E}_{1,2}$, and 0.3 for $2 \mathrm{E}_{0} / 1 \mathrm{E}_{1}$. Accordingly, the regressor trend had the values $0,0.3,0.5,0.6$, and 1 . Note that both regressors were statistically independent of each other due to balancing level combinations of number and trend over all conditions $(r=-0.016, \mathrm{P}<$ 0.96). To identify brain areas associated with number and those associated with trend, the effect of each regressor was assessed while the second factor was partialled out.

\section{RESULTS}

Behavioral Performance

Behavioral performance was assessed by error rates. If participants did not attend to the sequential structure of target motion, they were not able to detect 
sequential deviants within the last items within each trial $(P=0.5)$, resulting in a prediction performance at chance level. A repeated-measures ANOVA with the two-level factor TASK (sequence, baseline) indicated a significant main effect $(F(1,17)=273.9, P<0.0001)$, with an error rate of $22.8 \%$ for sequence and $1.9 \%$ for baseline In Fig. 1, mean error rates are indicated by a gray bar for each subcondition of sequence.

In a next step, a global ANOVA was computed over all subconditions with fully crossed factors number and trend, i.e., the six pure $E_{1}$ and $E_{0}$ sequences. The re peated-measures ANOVA with the three-level factor number $(1,2,3)$ and the two-level factor trend $(0,1)$ showed main effects for both number $(F(2,34)=256.2$, $\mathrm{P}<0.0001)$ and trend $(\mathrm{F}(1,17)=97.4, \mathrm{P}<0.0001)$ and a significant number $\times$ trend interaction $(F(2,34)=$ 21.7, $\mathrm{P}<0.0001$ ). As evident from Fig. 1, this interaction reflected increasing error rates for increasing sequential element number and an additional increase on each level of the factor number by increasing trend.

Finally, data were subjected to a stepwise multiple regression analysis with the independent variables number and trend $(r=-0.01663, \mathrm{P}<0.9636)$ and the error rate as the dependent variable. As a result, the variable number was the regressor with the highest correlation with the error rate, with an explained variance $\left(r^{2}\right)$ of $0.675(P<0.0035)$. Together with the variable trend, explained variance increased to $r=$ 0.799 ( $P<0.0036)$. However, while for the two-variable model the regression coefficient for number was statistically significant ( $P<0.0018$ ), the regression coefficient for trend only approached significance $(\mathrm{P}<$ 0.0761).

\section{MRI Data}

Effects of serial prediction. To identify the brain network involved in serial prediction, the two easiest levels of complexity of the serial prediction task (oneelement sequences) were collapsed and then contrasted with baseline, which controlled for perception, expectation of deviant detection, and motor responses. Thus by selecting sequence subconditions with almost perfect performance (3.1 and 3.5\% errors) for contrast with the condition baseline ( $1.9 \%$ errors), two experimental conditions were compared without confounding unspecific effects of difficulty, effort, or success.

Brain areas with significant BOLD response in se quence- basel ineare listed in Table 1 and shown in Fig. 2A. Activations were distributed dominantly within the right hemisphere, including foci located within the inferior ventrolateral premotor cortex (infPMv), the anterior inferior frontal sulcus (IFS), the anterior intraparietal sulcus (IPSa), the left cerebellar cortex (CE), and the head of the right caudate nucleus (CAU). Activation was most pronounced within the right infPMv.
Effects of sequential complexity measured by performance By means of parametric analysis, we investigated which brain areas covaried positively with the mean error rates (task difficulty) in each subcondition of sequence As listed in Table 2 and shown in Fig. 2B, local maxima were located in the same areas as in the sequence- baseline contrast, except for the IFS. Additional activations were located within the preSMA and SMA, the superior part of PMv (supPMv), the dorsolateral premotor cortex (PMd), the right frontal eye field (FEF), the left anterior and, bilaterally, the posterior portion of the IPS (IPSp), and two occipital areas near areas V4 and V5 within both hemispheres. Most pronounced activations were located within the supPMV and the IPSp.

Effects of sequential complexity measured by stimulus properties. Increasing the number of elements corresponded to increased activations in a large network of frontal and parietal areas, as listed in Table 2 and shown in Fig. 2C. Again, premotor cortices were dominantly activated, including the preSMA and SMA and the FEF, PMV, and PMd within both hemispheres, the latter extending into the primary motor cortex. Overall, the brain network that covaried with the number of sequential elements was as extended as that found to covary with the task difficulty. Activations were most pronounced within PMd and IPSp.

In contrast, the trend of sequences exposed positive covariance in fewer activation spots (Fig. 2D). These were located within the left preSMA, the right $F E F$, the right infPMv, the area $M T$, and an adjacent occipital area, probably corresponding to V4, within both hemispheres, and one spot within the right IPSa. Activations were most pronounced within infPMv and area V4.

The only regions that both were activated in sequence-baseline and covaried positively with increasing sequential complexity, as indicated by error rates and both physical parameters, i.e., element number and sequential trend, were the right infPMv and the corresponding parietal projection area, the right IPSa.

\section{DISCUSSION}

The present study was designed to investigate the brain correlates of increasing sequential complexity in observed target motion using whole-brain fMRI. Particularly, we focused on premotor areas where activations have been reported to increase with the production of increasingly complex sequential movement. A task that required serial prediction of structured target motion, but, in contrast to the classical SRT, not a sequential motor co- or reproduction, yielded significant activations in a network dominantly within the right hemisphere. Considered areas were the infPMv, the IPSa, the IFS, the CAU, and the CE. To facili- 
tate comparison, we have plotted the anatomical locations of the considered premotor and parietal network components as schematic spheres within an individual brain normalized to the standard Talairach size (Fig. 3).

Most interestingly for us, all involved brain areas, but particularly premotor areas, have been reported also to underlie the planning and production of motor sequences that follow an external sequential target stimulus, as particularly evident from imaging studies using the serial reaction task paradigm (Gordon et al., 1995; Grafton et al., 1995; Hazeltine et al ., 1997; Hikosaka et al., 1998, 1996; Honda et al., 1998; Sadato et al., 1996; Sakai et al., 1998; Toni et al., 1998). As expected, the present outcome indicates that an attentively observed sequential signal can be a stimulus sufficient to elicit activations within a brain network closely related to that one that participates in sequential motor be havior. It thereby confirms the results of prior related fMRI studies on serial prediction (Schubotz et al., 2000; Schubotz and von Cramon, 2001a,b, 2002a,b). In the following, we will focus our discussion mainly on the cortical regions of interest and on the background of their functions as evident from studies in humans and monkeys. Subsequently, we will discuss the effects of parametric contrasts.

\section{Serial Prediction Activates Ventrolateral Premotor Cortex and Anterior Intraparietal Sulcus}

The highest $Z$ scores and the largest extent of activation in serial prediction were found within the right PMv. Moreover, the right PMv was the only frontal area to be sensitive for all measures of sequential complexity, including behavioral measures and both physical measures, i.e., element number and sequential trend. The key function classically assigned to the lateral PM is the organization of sequential movement under sensory guidance, as indicated from research both in monkeys (Halsband and Passingham, 1985; Halsband et al., 1994; Kettner et al., 1996a,b; Mushiake et al., 1991) and humans (Deiber et al., 1991; Ellermann et al., 1998; Halsband and Freund, 1990; Halsband et al., 1993; Kawashima et al., 1994; Sadato et al., 1996; Van Oostende et al., 1997; Wessel et al., 1997) (for review, see Wise, 1985). Since sensoryguided movements are usually sequential movements, it may not be a mere coincidence that functions relating to both the sensory guidance of movement and the sequential organization of movement are supported within the same cortical structure. Thus, a sequence of movements responding to a sequence of guiding signals can be described as a step-by-step sensorimotor mapping process.

Finding the perceptual analysis of motion pattern to elicit vast activations within the PMv in the present study, our results are in line with these sensory and sensorimotor functions in monkey PM. In particular, together with evidence from SRT paradigms, our data indicate that perceptual representations and motor representations of sequential information are closely interconnected, if not at least partially realized, within the same premotor and parietal cortices. In this context, it is important to consider that increasing activations within the premotor-parietal network could not be caused by higher demands on the motor output level, because, in contrast to SRTs, there was no need for a transfer of a sensory signal into an open motor output in the presently employed SPT. Accordingly, increasing demands in serial prediction appear to draw on an earlier stage within the process of sensory-tomotor transformation or integration.

The present findings suggest that setting up a representation of a sequential pattern relies on brain areas that also support the preparation of movement, even if there is no need for a transfer of signal sequences into a corresponding motor response sequence. Evidence for this view comes also from behavioral findings that indicate that training on a perceptual task transfers automatically to a motor task (Howard et al., 1992; Meegan et al., 2001), a phenomenon referred to as "perception-action transfer." Nonetheless, sequential perception per se is not a guarantee for motor learning. An important aspect appears to be that perceptual or "observational learning" has to be explicit, i.e., conscious (Willingham, 1999; Kelly and Burton, 2001). More recent experiments have provided evidence that transfer between perception and action is bidirectional, as transfer both from action to perception and from perception to action was found (Hecht et al., 2001). These findings were taken to support the assumption of a "common coding" of perceptual and motor events (Prinz, 1997).

The finding that sequential information can transfer between perceptual and motor domains may imply that sequential representations reside in a processing level prior to the selection of effector systems to execute movement. This is also supported by cross-modal transfer of sequential representation (Keele et al., 1995). Using an adapted version of the SRT paradigm, Keele and co-workers (1995) showed that sequential knowledge transfers from an originally employed effector to a new effector system, e.g. from arm to fingers or vice versa. The authors therefore argue for a separated sequence representation and effector specification, as already proposed by Berkinblit and Feldman (1988).

Taken together, these findings support the assumption that sequential perceptual events can be represented independent of preparing an intended action toward the stimulus, while, moreover, representations of perceptual and motor events share a common neuronal basis. With regard to our present findings, we propose that the PM plays a crucial role in the repre- 
sentation of sequential information, whether it is perceptual or movement related.

Together with the right PMV, the right IPSa was found to be activated significantly more in sequence than in baseline and covaried positively with increasing sequential complexity as measured by error rates, el ement number, and trend. The IPS is the major projection zone of the lateral PM (Luppino et al., 1999; Matelli et al., 1998; Marconi et al., 2001; BattagliaMayer et al., 2001). It is formed by a multiplicity of functionally distinct areas that are strongly, reciprocally, and highly selectively connected with PM, and each of these circuits is supposed to be dedicated to a specific sensorimotor transformation (Rizzolatti et al., 1998; Matelli and Luppino, 2001). In several intraparietal subregions, object features are coded according to their pragmatic properties, for instance in reaching or grasping (Luppino et al., 1999).

This model is particularly interesting for the present findings. It indicates that areas that are crucial in transforming sensory information into target-directed motion get involved, even though we neither presented real objects nor instructed participants to imagine target-directed movements. We suggest that the premotor-parietal network activated by predicting a targets' pulsing motion reflects a sensorimotor integration of the targets' size and a corresponding hand grip, i.e., corresponding to the monkey "grasping circuit" connecting premotor area F5 and parietal AIP (Luppino et al., 1999). Evidence for this comes from fMRI findings that demonstrate that grasping in humans elicits activations within the human AIP homologue, with comparable Talairach coordinates (Binkofski et al., 1998, 1999).M oreover, coordinates of the presently found activations within PMV and IPSa are a very good replication of those reported in a recent study, where the same kind of stimuli and task were employed for a comparison between visual and auditory serial prediction (Schubotz and von Cramon, 2002a).

\section{Right Hemispheric Lateralization}

Lateral premotor, as coactivated areas, exposed a clear dominance within the right hemisphere. This is in line with the finding that even when sequences are performed or learned with the right hand, the right PM appears to play a greater rolethan its left homol ogue in sequential production (Seitz and Roland, 1992; J enkins et al., 1994; Sadato et al., 1996). Based on these and present findings, it could be suggested that there is a right premotor dominance not only in sequential production, but also in perceptual sequential processing. Moreover, the right and left hemispheres were found to reveal different competencies in mapping of sensory onto motor events, as for instance in imitation and matching of finger and hand postures. An impairment of these behaviors often can be observed in patients that suffer from a left parietal brain damage, giving rise to the clinical symptoms of apraxia (Ochipa and Gonzalez Rothi 2000; De Renzi et al., 1980). However, contrary to the apparent role of an intact left hemisphere, recent findings also point out the relevance of the right hemisphere. While the left hemisphere contributes mainly to body-part coding, the right hemisphere functions in the perceptual analysis of hand and finger postures that are to be matched or imitated (Goldenberg, 1999, 2001). We therefore conclude that the right hemisphere lateralization of activations found in serial prediction may be explained by the emphasis on perceptual analysis requirements.

This view is closely related to the finding that the right hemisphere has an advantage over the left hemisphere for temporally extended sensory guided movements (Velay and Benoit-Dubrocard, 1999) and sustained attention, as induced by the system's readiness to detect target signals over prolonged periods of time (Sarter et al., 2001). Hence, the right hemisphere supports global as compared to local information processing on the perceptual level (Fink et al., 1997; for overview, see Hellige, 1993). In the serial prediction task employed in the present study, global processing was required in so far as participants were required to set up a mental representation of temporally extended and structured, i.e., grouped, information. According to the above-mentioned findings, our result fits into the concept of sensory and sensorimotor advantages for global processing in the right brain.

\section{Correlates of Increasing Sequential Complexity \\ in Target Motion}

Behavioral and physical measures of sequential complexity covaried positively with PMv and al PS within the right hemisphere, areas which were al ready found in contrasting the easiest levels of the sequence task with the baseline task and whose functional meaning has been discussed above. With regard to other correlates found for our complexity manipulation, effects on both the behavioral and the brain levels reflected that the number of sequential elements and the sequential trend had an influence on the task difficulty and that the influence of sequential number was dominant in comparison to that of sequential trend. Brain effects of increasing prediction difficulty were nearly perfectly mirrored by brain effects of either increasing the number of sequential elements or increasing the sequential trend. In particular, some areas of this activation pattern were due to number manipulation (bilateral foci within the supPMV, PMd, IPSa, and IPSp), some were due to trend manipulation (area V4), and, finally, others were due to manipulations of both number and trend (preSMA, FEF, and area MT) (see Table 2). In the final paragraphs, we will turn to these findings. 
Increasing Either Number of Sequential Elements or Sequential Trend Increases Activation in Presupplementary Motor Area, Frontal Eye Fields, and Visual Motion Area

The parametric manipulations of sequential complexity yielded significant activations within the anterior part of the medial premotor cortex, corresponding to the preSMA. Like the lateral PM, the preSMA is known to play a crucial role in the control of sequential movement (Hikosaka et al., 1996, 1998; Picard and Strick, 1996; Sakai et al., 1998). In contrast to the lateral PM, however, the preSMA is especially important in the sequential organization of those movements that are internally guided and performed on the basis of memory (Goldberg, 1985; Passingham et al., 1989; Mushiake et al., 1991; Halsband et al., 1993). This implicates also a significant role in movement planning (Tanji and Shima, 1994; Tanji, 2001). Accordingly, it is crucial to note that response preparation effects were excluded in the present study, because effects of the choice reaction preparation were canceled out by contrast computation. Moreover, simple response preparation would make higher demands on the SMA proper, which is more closely related to motor execution and effector-specific modulations (Hummelsheim et al., 1988; Wiesendanger et al., 1985; Dum and Strick, 1991a,b; He et al., 1993; Tokuno and Tanji, 1993; Lu et al., 1994). In contrast, the functional characteristics of preSMA imply a higher hierarchical role in motor control than the SMA proper (Humberstone et al., 1997; Luppino et al., 1990, 1993; Rizzolatti et al., 1990, 1996; Matsuzaka et al., 1992).

The present findings reflect that the preSMA is involved not only in sequential motor organization, as suggested by findings in SRT paradigms, but also in sequential perceptual processes independent of further motor intentions. In particular, we take preSMA activation in serial prediction to reflect the requirement to set up specific expectations about ongoing events, i.e., a kind of prospective memory or "perceptual planning." According to this view, the preSMA is activated by the anticipation of and the attention to the forthcoming stimuli within the monitored stimulus sequence. This function has already been implied by studies on the so-called readiness potential (Kornhuber and Deecke, 1966; Y azawa et al ., 2000). In particular, it is suggested that the preSMA underlies sensory information processing in view of a potential decision making or motor selection for the action toward this sensory information (Ikeda et al., 1999). Evidence for this comes from imaging data demonstrating that the preSMA plays a major role in the detection of action obstacles by re sponse competition monitoring (Ullsperger and von Cramon, 2001). This mechanism serves to prevent erroneous responses to external events by triggering online adaptive behavior. Such a mechanism is especially induced whenever the system faces difficult or uncertain target-response mapping. If this interpretation is applied to the present data, increasing preSMA activation in increasingly difficult serial prediction reflects specifically high demands on an on-line adaptation of a virtual sequential response on a sequential target.

Medial premotor areas processing sensory information in view of motor selection parallels the lateral premotor function in sensorimotor integration. Particularly interesting for us, the preSMA was reported to underlie the shifting of motor plans in response to an instruction signal (Matsuzaka and Tanji, 1996) and the updating of a motor task between different series of sequential motor tasks (Shima et al., 1996). We therefore take the following view: While the lateral PM represents sequential sensory events automatically, as in their correspondence to sequential movements toward these stimuli, the preSMA provides a sequence template that has to be updated during the course of the trial and subsequently used to match perceived onto expected sequential events. This mechanism allows for a direct translation into an open motor production, but certainly without necessitating it. Accordingly, effects of increasing task difficulty within preSMA reflect the representation of templates of increasingly complex motor sequences, updated in correspondence to increasingly complex perceptual sequences.

Two further areas covaried with either physical measure of complexity, the right FEF and an occipital area within both hemispheres. We take both activations to reflect increasing visuospatial attentional demands. The production of increasingly long sequences of finger movements have yielded responses in the FEF in two recent PET studies (J enkins et al., 1994; Sadato et al., 1996) and is thus suggested to be engaged in the memory of visuospatially guided motor sequences. Moreover, the FEF were reported to be involved in predictive visual response to a future stimulus (Umeno and Goldberg, 1997), visual stimulus selection (Kodaka et al., 1997), or visuospatial orientation (Scalaidhe et al., 1997; Fujii et al., 1998). Thus, visuospatial attention probably was adapted to higher requirements in sequences with either more elements or higher sequential trend. Likewise, both of these factors were found to increase activation within an occipital region, probably area V5, which is also called motion area (MT) due to its role in motion perception (Zeki et al., 1991). Although motion was presented under all conditions, target motion differed systematically with regard to its intensity in dependence on number and trend. We therefore suggest that top-down attentional processes modulate neural responses within area $\mathrm{MT}$, as implicated by other studies (Treue and Maunsell, 1996; Treue and Martinez Trujillo, 1999; Friston and Büchel, 2000). 
Increasing Number of Sequential Elements I ncreases Activation in Dorsolateral Premotor Cortices and Intraparietal Sulcus within Both Hemispheres

Increasing the number of elements that built a pattern within the presented stimulus train increased activation within more dorsal parts of lateral PM, comprising spots within the superior PMV and the PMd. Correspondingly, additional activation foci were located within parietal projection zones, including the more dorsal anterior and posterior IPS within both hemispheres.

In contrast to more ventral premotor sites, PMd is particularly involved in perceptual visuospatial functions, with a specific role in mediating far space coding (Anderson et al., 1993; Rizzolatti et al., 1994; Petit et al., 1996; Boussaoud, 1995). Moreover, the PMd has recently been implicated in merging both near and far space (Iacoboni et al., 1997). According to this view, information that transcends near space into far space and vice versa might involve dorsal premotor areas. In the present study, participants reported that when the number of sequential elements was increased, the impression of a target moving back and forth in depth increased, while the impression of a regularly expanding/inflating and contracting/deflating target diminished. Indeed, a change of relative disparity is a sufficient binocular stimulus for the perception of motion in depth (Regan et al., 1995). The changing impression reported by the participants might have been reinforced by a stimulus feature that we employed to facilitate constant fixation; i.e., circles had an additional inlay circle filled with a different color. Note that the relative ratio between inner and outer circle size was constant over all stimuli to allow the impression of one identical target. When rules of spatial perspective are taken into account, the expansion of a target with, e.g., a diameter of $20 \mathrm{~mm}$ that expands for $20 \mathrm{~mm}$ in the two-dimensional plane on the presentation screen corresponds to a virtual approach of the same target that bisects an eye to screen observation distance of $1 \mathrm{~m}$. Accordingly, a stimulation that encourages the impression of three-dimensional motion in depth could have increased the demands on dorsal premotor functions in merging far and near space.

F urther evidence for this interpretation comes from areas that were activated by the same experimental manipulation, particularly the posterior intraparietal regions. Accordingly, while sequence-baseline and all manipulations of sequential complexity yiel ded activation within PMV and IPSa, only increasing sequential number yielded additional activations within PMd and IPSp (see Fig. 2). From study of monkeys we know that corresponding regions are intensively linked by reciprocal connections. Most simply one could say that the ventral "grasping circuit" links PMv (area F5) with an anterior intraparietal area, whereas the dorsal "reach- ing circuit" links PMd (area F 4) with the more posteriorly located intraparietal area (Luppino et al., 1999). Even though the correspondence of brain areas in monkeys and humans is still a matter of debate, we propose that additional activations in PMd and IPSp can be taken to reflect involvement of a second premotorparietal circuit, the reaching circuit. According to the functional interpretation in monkeys, increase within PMd-I PSp may reflect increasing requirements on the sensorimotor integration of the targets' spatial distance and the schema of a corresponding reaching movement. This hypothesis certainly remains to be tested by future studies.

Increasing Dynamic Trend within Sequences

Increases Activation in Area V4

All measures of increasing sequential complexity yielded significant bilateral activations within area MT, but the highest $Z$ scores for activations within area MT were found for the manipulation of sequential trend. Moreover, only increasing sequential trend caused additional local maxima of activation posteriorly and ventrally to area MT. Although a distinction between directly adjacent visual areas is difficult, the most probable location of this trend-specific additional activation is the visual area V4, according to comparisons between humans and monkeys (Van Essen et al., 2001). Functionally, area V4 has been suggested in size-constancy perception, a process that was extensively required to perform the serial prediction task. Note that intact size-constancy perception does not necessarily depend on intact motion perception, as evident from patient studies. Thus, an isolated misperception of the size of objects (in one hemifield), a socalled hemimicropsia, has been reported in a patient with a very focal lesion in $x=37.5 ; y=68 ; z=1$ (Kassubek et al., 1999). The authors suggest an area V4 affection, since this patient was not impaired in motion perception, which would have been the case if the lesion was in area MT. A role of area V4 in the perception of object size constancy is also suggested in monkeys (Schiller and Lee, 1991).

\section{A Premotor-Parietal Blueprint for Target Motion}

For the first time, the present study indicates that sequential complexity in attended target motion can be directly reflected by activation increase in premotor areas and their parietal projection zones. Together with evidence from sequential motor paradigms investigated by $\mathrm{FMRI}$ and PET, our findings support the view that sequential perceptual prediction and sequential motor planning are closely coupled not only functionally, but even anatomically within the human cortex.

Recently, it has been proposed that sequential programs are used as templates for extracting meaningful 
sequential information from sensory inputs and thereby form the basis for both perceptual prediction and goal-directed motor planning as a common substrate (Hommel et al., 2002). A close relation on the anatomical level has been suggested such that modifications of sensory representations automatically affect corresponding motor representations and probably also vice versa. Based on the present and earlier findings, we would support this view. However, the present study cannot settle ultimately what kind of representation is reflected by premotor activations in sequential perceptual prediction. This might be a motor scheme, a sensory target representation, or, finally, an integrated scheme-target representation, as suggested in models of the monkey brain (Fadiga et al ., 2000). Likewise, our findings cannot settle whether we predict sensory events such as target motion by motor planning or by imagery exactly because we imagine motor acts by predicting the sensory feedback that they effect, i.e., by sensory events. These issues remain to be investigated by future studies.

Speculating on present findings, one might suppose that when we attentively track a target motion and try to find out how its future course will probably look, the motor system generates a "blueprint" of the observed motion. With "blueprint" we mean the representation of a potential action related to the stimulus. The generation of such a blueprint of target motion can be interpreted as reflecting the automatic preparation for a fast stimulus-directed reaction. However, the greatest benefit might be that we can predict future target motion on the basis of this blueprint and thereby get the chance to move faster than the target. Accordingly, this blueprint of target motion might allow us to plan instead of merely react.

\section{ACKN O WLEDG MENTS}

We thank Marcel Brass, Evelyn Ferstl, and Thomas J acobsen for hel pful comments, Stefan Zysset, Gaby Lohmann, and Karsten Müller for support in MRI statistics, Andrea Gast-Sandman for support in graphic layout, and Katrin Sakreida for experimental assistance.

\section{REFERENCES}

Andersen, R. A., Snyder, L. H., Li, C. S., and Stricanne, B. 1993. Coordinate transformations in the representation of spatial information. Curr. Opin. Neurobiol. 3: 171-176.

Battaglia-Mayer, A., Ferraina, S., Genovesio, A., Marconi, B., Squatrito, S., Molinari, M., Lacquaniti, F., and Camiti, R. 2001. Eyehand coordination during reaching. II. An analysis of the relationships between visuomanual signals in parietal cortex and parietofrontal association projections. Cereb. Cortex 11: 528-544.

Berkinblit, M. B., and Feldman, A. G. 1988. Some problems of motor control. J . Mot. Behav. 20: 369-373.

Binkofski, F., Buccino, G., Posse, S., Seitz, R. J ., Rizzolatti, G., and Freund, H.-J . 1999. A fronto-parietal circuit for object manipulation in man: Evidence from a fMRI-study. Eur. J . Neurosci. 11: 3276-3286.
Binkofski, F., Dohle, C., Posse, S., Stephan, K. M., Hefter, H., Seitz, R. J ., and Freund, H.-J . 1998. Human anterior intraparietal area subserves prehension. Neurology 50: 1253-1259.

Boussaoud, D. 1995. Primate premotor cortex modulation of preparatory neuronal activity by gaze angle. J . Neurophysiol. 73: 886890.

Büchel, C., Holmes, A. P., Rees, G., and Friston, K. J . 1998. Characterizing stimulus-response functions using nonlinear regressors in parametric fMRI experiments. Neurol mage 8: 140-148.

Büchel, C., Wise, R. J . S., Mummery, C. J ., Poline, J .-B., and Friston, K. J . 1996. Nonlinear regression in parametric activation studies. Neurol mage 4: 60-66.

Deiber, M. P., Passingham, R. E., Colebatch, J. G., Friston, K. J ., Nixon, P. D., and Frackowiak, R. S. J . 1991. Cortical areas and the selection of movement: A study with PET. Exp. Brain Res. 84: 393- 402.

De Renzi, E., Motti, F., and Nichelli, P. 1980. I mitating gestures-A quantitative approach to ideomotor apraxia. Arch. Neurol. 37: 6-10.

Duhamel, J . R., Colby, C. L., and Goldberg, M. E. 1998. Ventral intraparietal area of the macaque: Congruent visual and somatic response properties. J . Neurophysiol. 79: 126-136.

Dum, R. P., and Strick, P. L. 1991a. The origin of corticospinal projections from the premotor areas in the frontal lobe. J. Neurosci. 11: 667- 689.

Dum, R. P., and Strick, P. L. 1991b. Premotor areas: Nodal points for parallel efferent systems involved in the central control of movement. In Motor Control: Concepts and I ssues (D. R. Humphrey and H.-J . Freund, Eds.), pp. 383-397. Wiley, New York.

Ellermann, J. M., Siegal, J. D., Strupp, J. P., Ebner, T. J ., and Ugurbil, K. 1998. Activation of visuomotor systems during visually guided movements: A functional MRI study. J . Magn. Reson. 131: 272-285.

Fadiga, L., Fogassi, L., Gallese, V., and Rizzolatti, G. 2000. Visuomotor neurons: Ambiguity of the discharge or 'motor' perception? Int. J . Psychophysiol. 35: 165-177.

Fink, G. R., Halligan, P. W., Marshall, J . C., Frith, C. D., Frackowiak, R. S., and Dolan, R. J . 1997. Neural mechanisms involved in the processing of global and local aspects of hierarchically organized visual stimuli. Brain 120: 1779-1791.

Fogassi, L., Gallese, V., Fadiga, L., and Rizzolatti, G. 1996a. Space coding in inferior premotor cortex (area F4): Facts and speculations. In Neural Bases of Motor Behaviour (F. Lacquaniti and P. Viviani, Eds.). Kluwer Academic, Dordrecht.

Fogassi, L., Gallese, V., Fadiga, L., Luppino, G., Matelli, M., and Rizzolatti, G. 1996b. Coding of peripersonal space in inferior pre motor cortex (area F4). J . Neurphysiol. 76: 141-157.

Friston, K. P. 1994. Statistical parametric maps in functional imaging: A general linear approach. Hum. Brain Mapp. 2: 189-210.

Friston, K., and Büchel, C. 2000. Attentional modulation of effective connectivity from V2 to V5/MT in humans. Proc. Natl. Acad. Sci. USA 97: 7591-7596.

Friston, K. P., Fletcher, P., J osephs, O., Holmes, A., Rugg, M. D., and Turner, R. 1998. Event-related fMRI: Characterizing differential responses. Neurol mage 7: 30-40.

Fujii, N., Mushiake, H., and Tanji, J . 1998. Intracortical microstimulation of bilateral frontal eye field. J . Neurphysiol. 79: 2240-2244.

Gentilucci, M., Fogassi, L., Luppino, G., Matelli, M., Camarda, R. M., and Rizzolatti, G. 1988. Functional organization of inferior area 6 in the macaque monkey. I. Somatotopy and the control of proximal movements. Exp. Brain Res. 71: 475- 490.

Gentilucci, M., Scandolara, C., Pigarev, I. N., and Rizzolatti, G. 1983. Visual responses in the postarcuate cortex (area 6) of the monkey that are independent of eye position. Exp. Brain Res. 50: 464- 468. 
Goldberg, G. 1985. Supplementary motor area structure and function: Review and hypotheses. Behav. Brain Sci. 8: 567- 616.

Goldenberg, G. 1999. Matching and imitation of hand and finger postures in patients with damage in the left or right hemisphere. Neuropsychologia 37: 559-566.

Goldenberg, G. 2001. I mitation and matching of hand and finger postures. Neurol mage 14: 132-136.

Gordon, A. M., Lee, J . H., Flament, D., Ugurbil, K., and Ebner, T. J . 1995. Functional MRI of cortical motor, sensory, and posterior parietal cortical areas during performance of sequential typing movements. Exp. Brain Res. 121: 153-166.

Grafton, S. T., Hazeltine, E., and I vry, R. 1995. Functional mapping of sequence learning in normal humans. J . Cog. Neurosci. 7: 497510.

Graziano, M. S., and Gandhi, S. 2000. Location of the polysensory zone in the precentral gyrus of anesthetized monkeys. Exp. Brain Res. 135: 259-266.

Graziano, M. S., Hu, X. T., and Gross, C. G. 1997. Visuospatial properties of ventral premotor cortex. J . Neurophysiol. 77: 22682292.

Halsband, U., and Freund, H. J . 1990. Premotor cortex and conditional motor learning in man. Brain 113: 207-222.

Halsband, U., Ito, N., Tanji, J ., and Freund, H. J . 1993. The role of premotor cortex and the supplementary motor area in the temporal control of movement in man. Brain 116: 243-266.

Halsband, U., Matsuzaka, Y., and Tanji, J . 1994. Neuronal activity in the primate supplementary, pre-supplementary and premotor cortex during externally and internally instructed sequential movements. Neurosci. Res. 20: 149-155.

Halsband, U., and Passingham, R. E. 1985. Premotor cortex and the conditions for movement in monkeys (Macaca fascicularis). Behav. Brain. Res. 18: 269-277.

Harrington, D. L., Rao, S. M., Haaland, K. Y., Bobholz, J . A., Mayer, A. R., Binder, J. R., and Cox, R. W. 2000. Specialized neural systems underlying representations of sequential movements. J . Cog. Neurosci. 12: 56-77.

Hazeltine, E., Grafton, S. T., and I vry, R. 1997. Attention and stimulus characteristics determine the locus of motor-sequence encoding. Brain 120: 123-140.

He, S. Q., Dum, R. P., and Strick, P. L. 1993. Topographic organization of corticospinal projections from the frontal lobe: Motor areas on the lateral surface of the hemisphere. J . Neurosci. 13: 952-980.

Hecht, H., Vogt, S., and Prinz, W. 2001. Motor learning enhances perceptual judgment: A case for action-perception transfer. Psychol. Res. 65: 3-14.

Hellige, J. B. 1993. Hemispheric Asymmetry: What's Right and What's Left. Harvard Univ. Press, Cambridge, MA.

Hikosaka, O., Miyashita, K., Miyachi, S., Sakai, K., and Lu, X. 1998. Differential roles of the frontal cotex, basal ganglia, and cerebellum in visuomotor sequence learning. Neurobiol. Learn. Mem. 70: 137-149.

Hikosaka, O., Sakai, K., Miyauchi, S., Takino, R., Sasaki, Y., and Pütz, B. 1996. Activation of human presupplementary motor area in learning of sequential procedures: A functional MRI study. J . Neurphysiol. 76: 617-621.

Holmes, A. P., and Friston, K. J . 1998. Generalisability, random effects and population inference. Neurol mage 7: 754.

Hommel, B., Müsseler, J ., Aschersleben, G., and Prinz, W. 2001. The theory of event coding (TEC): A framework for perception and action planning. Behav. Brain Sci. 24: $x-x$.

Honda, M., Deiber, M. P., I banez, V., Pascual-Leone, A., Zhuang, P., and Hallett, M. 1998. Dynamic cortical involvement in implicit and explicit motor sequence learning: A PET study. Brain 121: 21592173.
Howard, J . H., Mutter, S. A., and Howard, D. V. 1992. Serial pattern learning by event observation. J . Exp. Psychol. Learn. Mem. Cogn. 18: $1029-1039$.

Humberstone, M., Sawle, G. V., Clare, S., Hykin, J., Coxon, R., Bowtell. R. Macdonald, I. A., and Morris, P. G. 1997. FMRI of single motor events reveals human presupplementary motor area. Ann. Neurol. 42: 632- 637.

Hummelsheim, H., Bianchetti, M., Wiesendanger, M., and Wiesendanger, R. 1988. Sensory inputs to the agranular motor fields: A comparison of the precentral, supplementary-motor and premotor areas in the monkey. Exp. Brain Res. 69: 289-298.

Iacoboni, M., Woods, R. P., Lenzi, G. L., and Mazziotta, J . C. 1997. Merging of oculomotor and somatomotor space coding in the human right precentral gyrus. Brain 120: 1635-1645.

I keda, A., Yazawa, S., Kunieda, T., Ohara, S., Terada, K., Mikuni, N., Nagamine, T., Taki, W., Kimura, J., and Shibasaki, H. 1999. Cognitive motor control in human pre-supplementary motor area studied by subdural recording of discrimination/selection-related potentials. Brain 122: 915-931

J enkins, I. H., Brooks, D. J ., Nixon, P. D., Frackowiak, R. S. J ., and Passingham, R. E. 1994. Motor sequence learning: A study with PET. J . Neurosci. 14: 3775-3790.

J osephs, O., Turner, R., and Friston, K. 1997. Event-related fMRI. Hum. Brain Mapp. 5: 243-248.

Kassubek, J ., Otte, M., Wolter, T., Greenlee, M. W., Mergner, M. T., and Lücking, C. H. 1999. Brain imaging in a patient with hemimicropsia. Neuropsychologia 37: 1327-1334.

Kawashima, R., Roland, P. E., and O'Sullivan, B. T. 1994. Fields in human motor areas involved in preparation for reaching, actual reaching, and visuomotor learning: A PET study. J . Neurosci. 14: 3462-3474.

Kawashima, R., Tanji, J ., Okada, K., Sugiura, M., Sato, K., Kinomura, S., Inoue, K., Ogawa, A., and Fukuda, H. 1998. Oculomotor sequence learning: A positron emission tomography study. Exp. Brain Res. 122: 1- 8.

Keele, S. W., J ennings, P., J ones, S., Caulton, D., and Cohen, A. 1995. On the modularity of sequence representation. J . Mot. Behav. 27: 17-30.

Kelly, S. W., and Burton, A. M. 2001. Learning complex sequences: No role for observation? Psychol. Res. 65: 15-23.

Kettner, R. E., Marcario, J. K., and Clark-Phelps, M. C. 1996 a. Control of remembered reaching sequences in monkey. I. Activity during movement in motor and premotor cortex. Exp. Brain Res. 112: 335-346.

Kettner, R. E., Marcario, J . K., and Port, N. L. 1996b. Control of remembered reaching sequences in monkey. II. Storage and preparation before movement in motor and premotor cortex. Exp. Brain Res. 112: 347-358.

Kodaka, Y., Mikami, A., and Kubota, K. 1997. Neuronal activity in the frontal eye field of the monkey is modulated while attention is focused onto a stimulus in the peripheral visual field, irrespective of eye movement. Neurosci. Res. 28: 291-298.

Kornhuber, H. H., and Deecke, L. 1966. Hirnpotentialänderungen bei Willkürbewegungen und passiven Bewegungen des Menschen: Bereitschaftspotential und reafferente Potentiale. Pflüger Arch. Ges. Physiol. 284: 1-17.

Lekwuwa, G. U., and Barnes, G. R. 1996. Cerebral control of eye movements. II. Timing of anticipatory eye movements, predictive pursuit and phase errors in focal cerebral lesions. Brain 119: 491-505.

Lohmann, G., Mueller, K., Bosch, V., Mentzel, H., Hessler, S., Chen, L., Zysset, S., and von Cramon, D. Y. 2001. Lipsia-A new software system for the evaluation of functional magnetic resonance images of the human brain. Comput. Med. Imag. Graph. 25: 449-457. 
Lu, M. T., Preston, J . B., and Strick, P. L. 1994. Interconnections between the prefrontal and the premotor areas of the frontal lobe. J . Comp. Neurol. 341: 375-392.

Luna, B., and Sweeney, J. A. 1999. Cognitive functional magnetic resonance imaging at very-high-field: Eye movement control. Top. Magn. Reson. Imag. 10: 3-15.

Luppino, G., Matelli, M., and Rizzolatti, G. 1990. Corticocortical connections of two electrophysiologically identified arm representations in the mesial agranular frontal cortex. Exp. Brain Res. 82: 214-218.

Luppino, G., Matelli, M., Camarda, R., and Rizzolatti, G. 1993. Corticocortical connections of area F3 (SMA-Proper) and area F6 (PreSMA) in macaque monkey. J . Comp. Neurol. 338: 114-140.

Luppino, G., Murata, A., Govoni, P., and Matelli, M. 1999. Largely segregated parietofrontal connections linking rostral intraparietal cortex (areas AIP and VIP) and the ventral premotor cortex (areas F5 and F4). Exp. Brain Res. 128: 181-187.

Marconi, B., Genovesio, A., Battaglia-Mayer, A., Ferraina, S., Squatrito, S., Molinari, M., Lacquaniti, F., and Camiti, R. 2001. Eyehand coordination during reaching. I. Anatomical relationships between parietal and frontal cortex. Cereb. Cortex. 11: 513-527.

Matelli, M., and Luppino, G. 2001. Parietofrontal circuits for action and space perception in the macaque monkey. Neurol mage 14: 27-32.

Matelli, M., Govoni, P., Galletti, C., Kutz, D. F., and Luppino, G. 1998. Superior area 6 afferents from the superior parietal lobule in the macaque monkey. J . Comp. Neurol. 402: 327-352.

Matsuzaka, Y., Aizawa, H., and Tanji, J . 1992. A motor area rostral to the supplementary motor area (pre-supplementary motor area) in the monkey: Neuronal activity during a learned motor task. J . Neurophysiol . 68: 653-662.

Matsuzaka, Y., and Tanji, J . 1996. Changing directions of forthcoming arm movements: Neuronal activity in the presupplementary and supplementary motor area of monkey cerebral cortex. J . Neurophysiol. 76: 2327-2342.

Meegan, D. V., Aslin, R. N., and J acobs, R. A. 2001. Motor timing learned without motor training. Nat. Neurosci. 3: 860-862.

Mushiake, H., Inase, M., and Tanji, J . 1991. Neuronal activity in the primate premotor, supplementary, and precentral motor cortex during visually guided and internally determined sequential movements. J . Neurphysiol. 66: 705-718.

Nissen, M. J ., and Bullemer, P. 1987. Attentional requirements of learning: Evidence from performance measures. Cogn. Psychol. 19: 1-32.

Ochipa, C., and Gonzalez Rothi, L. J . 2000. Limb apraxia. Semin. Neurol. 20: 471- 478.

Passingham, R. E., Chen, Y. C., and Thaler, D. 1989. Supplementary motor cortex and self-initiated movement. In Neural Programming (M. Ito, Ed.), pp 13-24. J apan Sci. Soc., Tokyo.

Patel, A. D., and Balaban, E. 2000. Temporal patterns of human cortical activity reflect tone sequence structure. Nature 404: 8084.

Paus, T. 1996. Location and function of the human frontal eye field: A selective review. Neuropsychologia 34: 475- 483.

Petit, L., Orssaud, C., Tzourio, N., Crivello, F., Berthoz, A., and Mazoyer, B. 1996. Functional anatomy of prelearned sequence of horizontal saccades in humans. J . Neurosci. 16: 3714-3726.

Picard, N., and Strick, P. L. 1996. Motor areas of the medial wall: A review of their location and functional activation. Cereb. Cortex 6: 342-353.

Prinz, W. 1997. Perception and action planning. Eur. J . Cogn. Psychol. 4: 1-20.

Regan, D. 1995. Spatial orientation in aviation: Visual contributions. J . Vest. Res. 5: 455- 471.
Rizzolatti, G., Camarda, R., Fogassi, L., Gentilucci, M., Luppino, G., and Matelli, M. 1988. Functional organization of inferior area 6 in the macaque monkey. II. Area F5 and the control of distal movements. Exp. Brain Res. 71: 847- 856.

Rizzolatti, G., Gentilucci, M., Camarda, R. M., Gallese, V., Luppino, G., Matelli, M., and Fogassi, L. 1990. Neurons related to reachinggrasping arm movements in the rostral part of area 6 (area $6 a$ beta). Exp. Brain Res. 82: 337-350.

Rizzolatti, G., Luppino, G., and Matelli, M. 1996. The classic supplementary motor area is formed by two independent areas. Adv. Neurol. 70: 45-56.

Rizzolatti, G., Luppino, G., and Matelli, M. 1998. The organization of the cortical motor system: New concepts. Electroencephalogr. Clin. Neurophysiol. 106: 283-296.

Rizzolatti, G., Riggio, L., and Sheliga, B. M. 1994. Space and selective attention. In Attention and Performance XV: Conscious and Nonconscious Information Processing (C. Umilta and M. Moscovitch, Eds.), pp. 231-265. MIT Press, Cambridge, MA.

Rizzolatti, G., Scandolara, C., Matelli, M., and Gentilucci, M. $1981 b$. Afferent properties of periarcuate neurons in macaque monkey. II . Visual responses. Behav. Brain Res. 2: 147-163.

Rizzolatti, G., Scandolara, C., Matelli, M., and Gentilucci, M. 1981a. Afferent properties of periarcuate neurons in macaque monkey. I. Somatosensory responses. Behav. Brain Res. 2: 125-146.

Sadato, N., Campbell, G., Ibanez, V., Deiber, M., and Hallett, M. 1996. Complexity affects regional cerebral blood flow change during sequential finger movements. J . Neurosci. 16: 2691-2700.

Sakai, K., Hikosaka, O., Miyauchi, S., Takino, R., Sakaki, Y., and Pütz, B. 1998. Transition of brain activation from frontal to parietal areas in visuomotor sequence learning. J . Neurosci. 18: 18271840.

Sarter, M., Givens, B., and Bruno, J . P. 2001. The cognitive neuroscience of sustained attention: Where top-down meets bottom-up. Brain Res. Rev. 35: 146-160.

Scalaidhe, S. P., Rodman, H. R., Albright, T. D., and Gross, C. G. 1997. The effects of combined superior temporal polysensory area and frontal eye field lesions on eye movements in the macaque monkey. Behav. Brain Res. 84: 31- 46.

Schiller, P. H., and Lee, K. 1991. The role of the primate extrastriate area V4 in vision. Science 251: 251-253.

Schubotz, R. I., and von Cramon, D. Y. 2001a. Functional organization of the lateral premotor cortex: $\mathrm{fMRI}$ reveals different regions activated by anticipation of object properties, location and speed. Cogn. Brain Res. 11: 97-112.

Schubotz, R. I., and von Cramon, D. Y. 2001b. Interval and ordinal properties of sequences are associated with distinct premotor areas. Cereb. Cortex 11: 210-222.

Schubotz, R. I., and von Cramon, D. Y. 2002a. Predicting perceptual events activates corresponding motor schemes in lateral premotor cortex: An fMRI study. Neurol mage 15: 787-796.

Schubotz, R. I., and von Cramon, D. Y. 2002b. Dynamic patterns make the premotor cortex interested in objects: Influence of stimulus and task revealed by fMRI. Cogn. Brain Res., in press.

Schubotz, R. I., Friederici, D. A., and von Cramon, D. Y. 2000. Time perception and motor timing: A common cortical and subcortical basis revealed by fMRI. Neurol mage 11: 1-12.

Seitz, R. J ., and Roland, P. E. 1992. Learning of finger movement sequences: A combined kinematic and positron emission tomography study. Eur. J . Neurosci. 4: 154-156.

Shima, K., Mushiake, H., Saito, N., and Tanji, J . 1996. Role for cells in the presupplementary motor area in updating motor plans. Proc. Natl. Acad. Sci. USA 93: 8694-8698.

Talairach, J ., and Tournoux, P. 1988. Co-Planar Stereotaxis Atlas of the Human Brain. Thieme, New York. 
Tanji, J . 2001. Sequential organization of multiple movements: Involvement of cortical motor areas. Annu. Rev. Neurosci. 24: 631651.

Tanji, J ., and Shima, K. 1994. Role for supplementary motor area in planning several movements ahead. Nature 371: 413-416.

Thirion, J. P. 1998. Image processing as a diffusion process: An analogy with Maxwell's demons. Med. Image Anal. 2: 243-260.

Tokuno, H., and Tanji, J. 1993. Input organization of distal and proximal forelimb areas in the monkey primary motor cortex: A retrograde double labeling study. J . Comp. Neurol. 333: 199-209.

Toni, I., Krams, M., Turner, R., and Passigham, R. E. 1998. The time course of changes during motor sequence learning: A whole-brain fMRI study. Neurol mage 8: 50-61.

Treue, S., and Maunsell, J . H. 1996. Attentional modulation of visual motion processing in cortical areas MT and MST. Nature 382: 539-541.

Treue, S., and Maunsell, J. H. 1999. Effects of attention on the processing of motion in macaque middle temporal and medial superior temporal visual cortical areas. J. Neurosci. 19: 75917602.

Ullsperger, M., and von Cramon, D. Y. 2001. Subprocesses of performance monitoring: A dissociation of error processing and response competition revealed by event-related $\mathrm{FMRI}$ and ERPs. NeuroImage 14: 1387-1401.

Umeno, M. M., and Goldberg, M. E. 1997. Spatial processing in the monkey frontal eye field. I. Predictive visual responses. J . Neurphysiol. 78: 1373-1383.

Van Essen, D. C., Lewis, J . W., Drury, H. A., Hadjikhani, N., Tootell, R. B. H., Bakircioglu, M., and Miller, M. I. 2001. Mapping visual cortex in monkeys and humans using surface-based atlases. Vis. Res. 41: 1359-1378.

Van Oostende, S., Van Hecke, P., Sunaert, S., Nuttin, B., and Marchal, G. 1997. fMRI studies of the supplementary motor area and the premotor cortex. Neurol mage 6: 181-190.
Velay, J .-L., and Benoit-Dubrocard, S. 1999. Hemispheric asymmetry and interhemispheric transfer in reaching programming. Neuropsychologia 37: 895-903.

Wessel, K., Zeffiro, T., Toro, C., and Hallett, M. 1997. Self-paced versus metronome-paced finger movements: A PET study. J . Neuroimag. 7: 145-151.

Wiesendanger, M., Hummelsheim, H., and Bianchetti, M. 1985. Sensory input to the motor fields of the agranular frontal cortex: A comparison of the precentral, supplementary motor and premotor cortex. Behav. Brain Res. 18: 89-94.

Willingham, D. B. 1999. Implicit motor sequence learning is not purely perceptual. Mem. Cogn. 27: 561-572.

Wise, S. P. 1985. The primate premotor cortex: Past, present, and preparatory. Annu. Rev. Neurosci. 8: 1-19.

Wise, S. P., di Pellegrino, G., and Boussaoud, D. 1996. The premotor cortex and nonstandard sensorimotor mapping. Can. J . Physiol. Pharmacol. 74: 469-482.

Worsley, K., and Friston, K. 1995. Analysis of fMRI time-series revised-Again. Neurol mage 2: 359-365.

Yazawa, S., I keda, A., Kunieda, T., Nagamine, T., Taki, W., Kimura, J., Hori, T., and Shibasaki, H. 2000. Human presupplementary motor area is active before voluntary movement: Subdural recording of Bereitschaftspotential from medial frontal cortex. Exp. Brain Res. 131: 165-177

Zarahn, E., Aguirre, G. K., and D' Esposito, M. 1997. Empirical analysis of BOLD fMRI statistics. I. Spatially smoothed data collected under null-hypothesis and experimental conditions. NeuroImage 5: 179-197.

Zeki, S., Watson, J . D. G., Lueck, C. J ., Friston, K. J ., Kennard, C., and Frackowiak, R. S. J . 1991. A direct demonstration of functional specialization in human visual cortex. J . Neurosci. 11: 641- 649.

Zhuang, P., Dang, N., Waziri, A., Gerloff, C., Cohen, L. G., Hallett, M., and Waziri, A. 1998. Implicit and explicit learning in an auditory serial reaction time task. Acta Neurol. Scand. 97: 131-137. 